http://jmscr.igmpublication.org/home/ ISSN (e)-2347-176x ISSN (p) 2455-0450 crossref DOI: https://dx.doi.org/10.18535/jmscr/v8i1.87

\title{
Effectiveness Evaluation of percutaneous Trigger Finger Release
}

\author{
Authors \\ Dr Manoj.M.K ${ }^{1}$, Dr Aryamol.M.K ${ }^{2}$, Dr Vaisakh.V.K ${ }^{3}$ \\ ${ }^{1}$ Associate Professor, Department of Orthopedics, Government Medical College Trichur \\ ${ }^{2}$ Assistant Professor, Department of Medicine, Government Medical College Trichur \\ ${ }^{3}$ Resident, Departmentt of orthopedics, Government Medical College Trichur
}

\begin{abstract}
Objective: In this study, we aimed to evaluate the results of percutaneous release of Trigger Finger using $18 G$ needle in 30 patients.

Methods: From November 2017 to November 2018, 30 patients with Trigger Finger were treated with percutaneous A1 pulley release using $18 G$ needle at Govt Medical College, Trichur. Surgeons included Final Year Post Graduates Students to Professor/Unit Chiefs. Mean follow up period was 15 weeks. Results were classified as satisfactory when there was complete relief from complaints and unsatisfactory when there was persistence of complaint or if open surgery were required.

Results: 25(83.3\%) patients had complete relief from triggering and there complaints.3(10\%) patients had to undergo open release after repeated attempt of needling. 2 (6.7\%)patients who complained of persistent pain at the needling site, despite relief of the triggering were relieved of pain after single shots of local steroid injection.

Conclusion: Needle release of trigger finger is effective, safe and well tolerated by patients. It should be done by senior Orthopedic or Hand Surgeon to avoid any complication.
\end{abstract}

\section{Introduction}

Stenosing tenosynovitis or trigger finger is generally characterized by pain, swelling, limitation of finger motion and a triggering sensation. The most commonly involved digit is reported to be the ring finger or thumb with the index and small fingers being the least symptomatic. The primary pathology is thickening of the A1 pulley with resultant entrapment of the flexor tendon, thus forming a triggering mechanism. Although synovial proliferation and fibrosis of flexor sheath are identified as triggering factors, there is no consensus in the literature about its true cause and its aetiology remains unknown. Notta in 1850 first described trigger finger as a condition caused by changes to the flexor tendon and its sheath. Hueston and Wilson demonstrated in an anatomical study that the spiral arrangement of the architecture of the intra tendon fibres leads to the formation of nodules that form distally to the A1 pulley.

Treatment for trigger finger ranges from NSAID's, splinting of the finger, Steroid Injection, Closed release to open release of A1 pulley. Steroid injection, anti-inflammatory drug use and splinting of the finger are among the conservative treatment measures. Less than 6 months after onset of symptoms, triggering can 
be effectively treated by NSAIDs and other conservative measures. The success of conservative treatment is reported to be $50-92 \%$ in the literature. According to Kevin Kang, MD, cortisone injections have only a $57 \%$ effective rate. In 1958 Lorthioir first described a technique of percutaneous release using a fine tenotome. Eastwood et al described percutaneous release using a hypodermic needle. Several methods using various instruments have been reported with satisfactory results and few complications e.g. HAKI Knife; Solco, Seoul Korea. Common Complications of surgical treatment include incomplete release, injury to tendon, vessels and nerves, scar tenderness, joint contractures and infection.

In this study, we aimed to evaluate the results of percutaneous release of Trigger Finger using 18G needle in 30 patients.

\section{Patients and Methods}

Total Number of patients was 30 . There were 5 males and 25 females. 23 cases were in Right Hand and 7 cases in Left hand. Thumb was involved in 4 cases, Index finger in 6 cases, ring Finger in 10 cases and mid finger in 10 cases. 14 patients had DM and 1 patients had RA. 14 patients were graded (Green's Classification) as grade 11 and 16 patients were graded as grade 111 . No patient had prior steroid injection at the triggering site. The mean duration of symptoms before treatment was 8.4 Months.

\begin{tabular}{|c|c|}
\hline MALE & 5 \\
\hline FEMALE & 25 \\
\hline RIGHT & 23 \\
\hline LEFT & 7 \\
\hline \multicolumn{2}{|c|}{} \\
\hline THUMB & 4 \\
\hline INDEX & 6 \\
\hline MID & 10 \\
\hline RING & 10 \\
\hline
\end{tabular}

\begin{tabular}{|c|c|}
\hline $\begin{array}{c}\text { TRIGGER FINGER } \\
\text { STAGING }\end{array}$ & No Of Cases \\
\hline Grade 11 & 14 \\
\hline Grade 111 & 16 \\
\hline
\end{tabular}

In Preoperative Ward all patients were given Lignocaine test Dose, 1st dose of Oral antibiotics and Normal Saline IV infusion started with $18 \mathrm{G}$ Cannula. Informed Consent was taken prior to entering the OT. The mean operative time for successful percutaneous A1 pulley release was $9.5 \mathrm{~min}(8-14)$, including the local anesthesia of the patient. Duration of Follow up was between 12 weeks to 18 weeks.

2 patients (1 thumb and $1 \mathrm{mid}$ finger) had persistent pain at the site of release, despite relief of the triggering. Both the patients, local steroid injection relieved there pain. No case of restenosis seen.3 patients had to undergo open release immediately since triggering persisted even after repeated needling. In all 3 patients, intraoperative observation revealed incomplete release of the A1 pulley. Significant complications, such as injuries to the digital nerve, infection or bowstringing of the flexor tendons were not encountered. Dressing is given for $24 \mathrm{hrs}$ minimum or maximum of 3 days only (no specific reason).

\section{Method}

TRIGGER FINGER STAGING: Green's classification

- Grade I (pretriggering) - Pain; history of catching that is not demonstrable on clinical examination; tenderness over the A1 pulley

- Grade II (active) - Demonstrable catching, but the patient can actively extend the digit

- Grade III (passive)- Demonstrable locking, requiring passive extension (grade III A) or inability to actively flex (grade III B)

- Grade IV (contracture)- Demonstrable catching, with a fixed flexion contracture of the PIP joint

A1 pulley release for Trigger Finger was done under local anaesthesia using $18 \mathrm{G}$ needle on 30 patients. Procedure was done by all members in the Orthopaedic Unit from Final Year Post Graduate Students under guidance of principal investigator to Unit Chiefs/ professor. 
Technique of identifying Al Pulley: A1 pulley is located by palpating the point of triggering.Near the distal horizontal palmar crease, proximal edge of the A-1 pulley is located for the small, ring, and middle fingers and for the index finger it is located at the proximal horizontal palmar crease.

A1 pulley release is relatively safe for the ring and middle fingers compared to the index and small finger due to the oblique course of the flexor tendons and neurovascular structures in the index and small finger.

Preferent insertion site of the needle in the thumb is the intersection point of the proximal thumb digital crease and perpendicular line up the central axis of the palmar aspect.Oblique course of the radial neurovascular bundle from ulnar to radial across the A1 pulley of the thumb makes it vulnerable to injury during the procedure.

Technique of needle insertion: The needle may be first inserted into the tendon and the same may be confirmed by needle movement when the patient flexes and extends the distal phalanx. Slowly the needle is withdrawn until this motion ceases. Cessation of motion confirms the presence of needle tip is now inside the A-1 pulley.Once the position of the needle tip is confirmed the A-1 pulley is cut only in the longitudinal axis of the flexor tendon sheath by moving the needle forward and back.The pulley being cut generates a grating sensation and the release is adequately checked after the needle is withdrawn and the patient is asked to flex and extend the digit to show relief from triggering.

Return to their daily activity depends on their confidence and relief of symptoms, usually after 5-7 days. Positions that require manual labour may require 2 weeks before returning to work.

\section{Results}

25(83.3\%) patients had complete relief from triggering and there complaints.3 (10\%) patients had to undergo open release after repeated attempt of needling (done by final year Post Graduate Students under supervision). 2 (6.7\%) patients who complained of persistent pain at the needling site, despite relief of the triggering were relieved of pain after single shots of local steroid injection (Painful tenosynovitis without triggering often occurs in patients after a percutaneous release. This may be a result of the high rate of flexor tendon scoring).

\begin{tabular}{|c|c|}
\hline complete relief & $25(83.3 \%)$ \\
\hline open release & $3(10 \%)$ \\
\hline persistent pain & $2(6.7 \%)$ \\
\hline Digital Nerve Injury & Nil \\
\hline Tendon Rupture & Nil \\
\hline Recurrence & Nil \\
\hline Infection & Nil \\
\hline
\end{tabular}

\begin{tabular}{|c|c|c|}
\hline Study & $\begin{array}{l}\text { Number } \\
\text { of Cases }\end{array}$ & Complications \\
\hline Present Study & 30 & $\begin{array}{l}\text { 1. open release } 3 \text { cases } \\
\text { 2. persistent pain } 2 \text { cases }\end{array}$ \\
\hline Haki et al & 185 & No Complications \\
\hline Amrani et al & 63 & Recurrence 2 cases \\
\hline $\begin{array}{l}\text { Eastwood et } \\
\text { al }\end{array}$ & 35 & $\begin{array}{c}\text { Partial symptomatic relief } \\
2 \text { cases }\end{array}$ \\
\hline $\begin{array}{l}\text { Issam } \\
\text { Dahadra et al }\end{array}$ & 42 & $\begin{array}{c}\text { Residual Triggering } 3 \\
\text { cases }\end{array}$ \\
\hline $\begin{array}{l}\text { Rami Ahmed } \\
\text { Diab }\end{array}$ & 43 & $\begin{array}{l}\text { 1. Incomplete Release } 3 \\
\text { cases } \\
\text { 2. Superficial Tendon } \\
\text { Laceration } 6 \text { cases }\end{array}$ \\
\hline Z Marij et al & 52 & No Complications \\
\hline Bakir Yuvuz & 48 & No Complications \\
\hline
\end{tabular}

\section{Discussion}

Trigger finger is a condition for which there are many treatment modalities. Conservative treatment involves NSAIDs, Injection of steroids/local anaesthetics and splint application. In patients who did not benefit from conservative treatment, surgery is performed which involves release of A1 pulley. Debates between the alternatives of open surgery and the percutaneous release procedure are still continuing. the percutaneous release has been popular with observations favoring its ease of application, lower cost and complication rates. This procedure was first described by Lorthiori in 1958 using a fine tenotome. He reported good results in all case. Surgeons reported fewer complications with percutaneous release, such as incision related 
infections, formation of painful scars, bowstringing of flexor tendons due to pulley injury, joint nodules, weakness and digital nerve injury seen with conventional open surgery.

Our study study showed complications and residual triggering in 5 cases which is comparable to the studies by Amrani et al, Rami Ahamed Diab et al and Issam Dahadraet et al. Studies done by Haki et al, Z Marij and Bakir Yuvuz et al produced no complications.

Division of the A1 pulley usually causes minimal morbidity. Near normal hand function can be maintained with only the A2 and A4 annular pulley intact. The increased work of flexion that has been shown biomechanically after A1 pulley excision does not appear to be relevant clinically for most patients.A2 pulley injuries in rock climbers and reports of patients who have had part of their A2 pulley transected surgically show the importance of preserving this pulley in preventing bowstringing of the flexor tendon. Biomechanical studies of pulley excision showed increase in work for finger flexion after A2 pulley excision and a marked increase after removal of both A1 and A2 pulley. Anatomic studies have shown nearly $50 \%$ incidence of continuity between the A1 and A2 pulleys. The separation between two pulleys generally is 0.4 to $4.1 \mathrm{~mm}$. When it is not present, however, there is a sliver of retinacular tissue at the site of separation. Care should be taken not to extend a surgical release into the substance of the A2 pulley.

\section{Conclusion}

Percutaneous release of trigger finger using18G Needleis not only effective, safe and well tolerated by patients but also avoids time and expense of an open procedure. It should be done by senior Orthopedic or Hand Surgeon to avoid complications.

\section{References}

1. Mark Ryzewicz, MD, Jennifer Moriatis Wolf, MD Trigger Digits: Principles, Management, and Complications From the
Department of Orthopaedics, University of Colorado Health Sciences Center, Denver, CO.

2. Fleisch SB, Spindler KP, Lee DH. Corticosteroid injections in the treatment of trigger finger: a level I and II systematic review. $J$ Am Acad Orthop Surg 2007;15:166-71.

3. Percutaneous release of trigger digits,a technique and results using a specially designed knife K. I. Ha, M. J. Park, C. W. Ha From Sungkyunkwan University School of Medicine, Seoul, Korea

4. Kolind-Sorensen V. Treatment of trigger fingers. Acta Orthop Scand1970;41:42832.

5. Clark DD, Ricker JH, MacCollum MS. The efficacy of local steroid injection in the treatment of stenosing tenovaginitis. Plast Reconstr Surg 1973;51:179-80. Rhoades CE, Gelberman RH, Manjarris JF.

6. Stenosing tenosynovitis of the fingers and thumb: results of a prospective trial of steroid injection and splinting. Clin Orthop 1984;190:236-8. Marks MR, Gunther SF.

7. Efficacy of cortisone injection in treatment of trigger fingers and thumbs. J Hand Surg [Am] 1989;14:722-7. Murphy D, Failla JM, Koniuch MP.

8. Steroid versus placebo injection for trigger finger. J Hand Surg [Am] 1995;20:62831.Quinnell RC.

9. Conservative management of trigger finger. Practitioner 1980;224:187-90. Newport ML, Lane LB, Stuchin SA.

10. Treatment of trigger finger bysteroid injection. J Hand Surg [Am] 1990;15:74850.8. Benson LS, Ptaszek AJ.

11. Injection versus surgery in the treatment of trigger finger. J Hand Surg [Am] 1997;22A:138-44.Turowski GA, Zdankiewicz PD, Thomson JG. 
12. The results of surgical treatment of trigger finger. J Hand Surg [Am] 1997;22:145-9. Lorthioir J.

13. Surgical treatment of trigger finger by a subcutaneous method. J Bone Joint Surg [Am] 1959;40-A:793-5.11. Tanaka J, Muraji M, Negoro H, et al.

14. Subcutaneous release of trigger thumb and fingers in 210 fingers. J Hand Surg [Br] 1990;15:463-5. Eastwood DM, Gupta KJ, Johnson DP.

15. Percutaneous release of the trigger finger: an office procedure. $\mathrm{J}$ Hand Surg [Am]1992;17:114-7.13. Lyu S-R.

16. Closed division of the flexor tendon sheath for trigger finger.J Bone Joint Surg [Br] 1992;74-B:418-20.14. Patel MR, Moradia VJ.

17. Percutaneous release of trigger digit with and without cortisone injection. J Hand Surg [Am] 1997;22:150-5 Cihantimur B, Akin S, Ozcan M.

18. Percutaneous treatment of trigger finger: 34 fingers followed 0.5-2 years. Acta Orthop Scand 1998;69:167-8.Bain GI, Turnbull J, Charles MN, Roth JH, Richards RS.

19. Percutaneous A1 pulley release: a cadaveric study. J Hand Surg [Am]1995;20:781-4. Pope DF, Wolfe SW.

20. Safety and efficacy of percutaneous trigger finger release. J Hand Surg [Am] 1995;20:280-3

21. Complications of Percutaneous Release of the Trigger Finger Alper Aksoy, Emin Sir

22. Percutaneous Release of trigger Finger RamiAhmed Diab Journal of Orthopaedic Surgery 2015;23(2):241-2

23. Percutaneous Surgery: A Safe Procedure for Trigger Finger? Bekir Yavuz Uçar North American Journal of Medical Sciences Sep 2012.
24. Percutaneous trigger finger release with 18G needle Saudi Medical j 2007Issam Dahabra. 